\title{
Para tirar o leitor da toca: o papel do narrador em O hobbit, de Tolkien
}

\author{
To take out the reader from the hole: the role of the \\ narrator in The Hobbit, by Tolkien
}

\section{Eliane Aparecida Galvão Ribeiro*}

Resumo: Este texto tem por objetivo apresentar uma possibilidade de leitura da obra O hobbit, de Tolkien (1998), na qual se considera o papel do leitor e do narrador. Para a consecução do objetivo, pretende-se refletir, a partir das contribuições da estética da recepção, acerca do que propicia o prazer na leitura e quais elementos determinam o papel do leitor implícito e as disposições do narrador. Constrói-se, neste texto, a hipótese de que a estratégia do escritor de apresentar sua narrativa sob a forma de um romance de formação permite ao jovem, também em fase de definição de sua personalidade, identificação com a temática.

\begin{abstract}
This text aims to provide an opportunity to read the piece The hobbit, of Tolkien (1998), and make a reflexion about the role of the reader and narrator. To achieve this goal, we intend to reflect, from the contributions of reception aesthetics, about what provides the pleasure in reading and what factors determine the role of implied reader and the provisions of the narrator. It builds up in this text, the hypothesis that the strategy of the writer to present his narrative in the form of a novel training allows the young, also in the definition phase of his personality, identification with the subject.
\end{abstract}

Palavras-chave: estética da recepção, literatura juvenil, leitor, narrador.

Keywords: aesthetics of reception, juvenile literature, reader, narrator.

\footnotetext{
* Possui Graduação em Letras (1988); mestrado (2003) e doutorado (2009) em Letras pela Universidade Estadual Paulista Júlio de Mesquita Filho (UNESP-Assis). Exerce a função de professora assistente doutora na UNESP/Assis.
} 


\title{
Introdução
}

\begin{abstract}
A relação entre os textos e os leitores é a origem e o centro de uma das linhas que parecem mais promissoras do progresso futuro deste campo: a de entender as características dos textos como uma proposta de formação e ajuda ao leitor em seu itinerário de acesso à literatura como discurso social, que configura e expressa a experiência humana. (COLOMER, 2003, p.386)
\end{abstract}

A obra fantástica O hobbit, de John Ronald Reuel Tolkien (1892-1973), surgiu, aproximadamente, em 1930 ou 1931, sob a forma de história oral para seus filhos. O livro foi publicado, somente, em setembro de 1937, na Grã-Bretanha. No ano seguinte, com sua publicação nos Estados Unidos, pela Houghton Mifflin, recebeu o Prêmio do New York Herald Tribune pelo melhor livro juvenil (White, 2002, p.170).

Concebe-se, neste texto, a obra fantástica em consonância com Held (1980, p.23), como a que propõe ao leitor o que parece inimaginável, levando-o a examinar mais de perto as relações entre real e imaginário. Para a autora, o fantástico opõe-se ao real, pois sua fonte é a fantasia. Conforme Aguiar (2005), o prazer da leitura de uma obra fantástica para os jovens advém, justamente, dessa possibilidade de vivência da fantasia.

A afirmação de Aguiar (2005) é válida, principalmente, se verificarmos que $O$ hobbit, assim como a trilogia Senhor dos Anéis, de Tolkien, que lhe confere continuidade, tem sido fenômeno de vendas (Tolkien Brasil, 2014). A série foi apropriada pelos jovens e aparece, em listas de vendas mundiais, entre as dez primeiras colocadas. Contudo, vale destacar que mais de um terço de suas vendas ocorreram após o lançamento das adaptações da Warner Brothers para o cinema, dirigidas por Peter Jackson. A obra $O$ hobbit, embora não tenha o mesmo sucesso da trilogia Senhor dos Anéis, também é um fenômeno de vendas, perdendo, apenas, para $O$ pequeno príncipe, de Saint-Exupéry e Harry Potter e a pedra filosofal, de Rowling, nas listas de "mais vendidos" mundialmente (Tolkien 
Brasil, 2014). Sua adaptação para o cinema, também pela Warner e dirigida por Jackson, dividiu-se em três partes. A primeira intitulou-se $O$ hobbit: uma jornada inesperada (2012) e a segunda, O hobbit: a desolação de Smaug (2013). A terceira tem previsão de lançamento para este ano e, provavelmente, terá como título O hobbit: lá e de volta outra vez (Site Oficial da Warner, 2014).

Neste texto, objetiva-se apresentar uma análise da obra $O$ hobbit, de Tolkien (1998), na qual se pretende refletir, a partir das contribuições da estética da recepção, acerca do papel do leitor implícito e das disposições do narrador. Constrói-se, neste texto, a hipótese de que a apresentação da narrativa sob a forma de romance de formação permite ao jovem, que busca definir sua personalidade, identificar-se com a temática. Além disso, acredita-se que, pelo apelo à reflexão, a obra é emancipatória e, por considerar seu leitor, estabelece comunicabilidade, facultando-lhe, assim, prazer na leitura.

Para a consecução do objetivo, parte-se do pressuposto, conforme Zilberman (1984, p.133), de que os polos entre os quais o narrador oscila são: o recurso aos comentários ou à afluência de lacunas. A quantidade de um ou de outro indicia o tipo de domínio que exerce sobre o deciframento da história e, por extensão, do leitor implícito. A presença de vazios instaura a comunicabilidade; já a predominância de comentários, a autoridade do narrador. Essa autoridade restringe a participação do leitor. Justifica-se, então, o título deste artigo, uma vez que se acredita que a obra de Tolkien, por estabelecer comunicabilidade com o leitor, convida-o a sair da "sua toca", ou seja, da zona de conforto, para interagir durante a leitura.

\section{O fantástico e o leitor}

Em O hobbit, Tolkien cria uma mitologia autônoma que se distancia da realidade observada e, imersa na fantasia, aproxima-se da mitologia europeia. Justifica-se, então, que a fantasia seja o aspecto mais relevante para os jovens quando apontam as qualidades dessa obra, sendo seguida pela aventura, pelo suspense e pela dialogia. Essa detecção pôde ser realizada em pesquisa de campo desenvolvida durante quatro anos com cerca de 50 jovens leitores (Ferreira, 2009).

Colomer (2003, p.223) afirma que a fantasia é, também, um instrumento privilegiado de denúncia da sociedade pós-industrial. Assim, pode-se observar na 
obra de Tolkien, imersa na Antiguidade, uma desqualificação dessa sociedade. Para a autora, a fantasia em algumas obras reformula a ideia de uma aliança natural entre a figura do artista e de seu público cúmplice, ante a hostilidade ou ignorância da sociedade produtiva moderna. Justamente, o saber, em $O$ hobbit, representa um resgate do mundo anterior à ciência moderna. Nesse mundo, a dimensão de temporalidade situa-se no passado, em uma dimensão de contínua duração, mas que não consta do calendário.

De acordo com White (2202, p.171), a obra de Tolkien, foi publicada no outono de 1937, no contexto de horrores em que "[...] Guernica, na Espanha, fora extinta pelos fascistas, e em setembro os japoneses arrasaram Xangai, matando milhares de inocentes." Na Grã-Bretanha, as pessoas sabiam que a guerra era inevitável, assim, O hobbit oferecia-Ihes para leitura um mundo alternativo, sem morteiros, bombas incendiárias e nazistas em marcha.

Em sua crítica às formas de vida da sociedade pós-industrial, $O$ hobbit assume o que Todorov (1970, p.161) define como função social do fantástico, que se converte em um meio de combate à censura institucionalizada e a mais sutil que reina na psique dos autores, pois por meio dele, pode-se tratar de temas complexos. Efetiva-se, na obra de Tolkien, uma crítica às formas de vida na sociedade. Pela sua leitura, nota-se que os temas trazem para o centro da narrativa o questionamento das relações em sociedade. Tolkien revela que, nessas relações, existem preconceitos diversos relacionados à raça (anões, elfos, hobbits, homens) e à competência mágica dos indivíduos. Assim, se os espaços permanecem associados ao passado, os temas, pela atualidade, permitem identificações com o leitor contemporâneo.

Vale destacar que a opção do autor em se afastar da realidade observada e ofertar outra alternada, assegura a atmosfera da narrativa fantástica, cuja matéria provém da mesma origem dos sonhos. $O$ contato do jovem leitor com essa realidade mais humana, leva-o a indagar a sua realidade e a desejar que esta seja diferente. Assim, a obra promove nesse leitor desejos de mudança social. Trata-se, então, da função psicanalítica do fantástico que Smadja (2004, p.30) afirma ter por objetivo enganar a censura do Ego. A esta, a autora acrescenta outras duas: a estética, que faculta ao escritor conceder a sua obra o encanto do exotismo proveniente do universo mágico; e a pedagógica, que lhe permite transmitir uma mensagem moralizadora sem que esta tenha o peso de uma lição de moral. 


\section{O narrador e seu convite ao leitor}

O tema central de $O$ hobbit é a autodescoberta. Para tanto, o protagonista, Bilbo Bolseiro, um hobbit egocêntrico e abastado que reside em uma confortável toca no flanco de uma colina, ingressa na aventura. Essa personagem define-se pela dualidade, pois possui gosto pela aventura, que provém de seus ancestrais Tûk, mas também, graças ao sangue Bolseiro, pela vida com bastante conforto. Apesar disso, em uma manhã, o mago Gandalf chega à vila de Bilbo, a fim de incluí-lo em uma jornada. Gandalf crê na competência desse hobbit, embora o próprio duvide disso. Para motivá-lo, coloca-o em contato com doze anões que, por meio de relatos de viagem e cantorias, despertam, no protagonista, sua porção Tûk. Bilbo ingressa, então, na aventura de resgate ao tesouro dos anões, roubado pelo dragão Smaug. Durante a jornada, ele é preso, ferido, enganado, mas encontra um anel que Ihe faculta o poder da invisibilidade. Com a ajuda desse anel, passa a auxiliar o grupo de anões, já que Gandalf precisa se afastar, deixando-os na trilha que leva à montanha de Smaug.

O mago retorna quando os anões, de posse do tesouro, instauraram uma guerra com os povos vizinhos, pois se recusam a lhes dar uma participação na riqueza. Bilbo é o único que não se deixa levar pela ganância. Enquanto elfos, anões e os homens do lago brigam pelo tesouro, os orcs se aproximam buscando vingança. Trava-se uma batalha mortal, da qual Bilbo, Gandalf e alguns anões sobrevivem. No retorno para sua vila, Bilbo está mais sábio, pois descobriu potenciais dos quais sequer suspeitava.

A enunciação em $O$ hobbit é constituída por uma voz marcada pela intenção do narrador de contar uma história que instigue seu leitor. Para tanto, esse narrador configura seu discurso sob a forma de um diálogo descontraído que, pela apresentação de uma personagem inusitada, desprovida de definição e situada em um cenário surpreendente, instaura o vazio:

Numa toca no chão vivia um hobbit. Não uma toca desagradável, suja e úmida, cheia de restos de minhocas e com cheiro de lodo; tampouco uma toca seca, vazia e arenosa, sem nada em que sentar ou o que comer: era a toca de um hobbit, e isso quer dizer conforto. (TOLKIEN, 1998, p.2).

Seu discurso, pelo emprego de verbos no pretérito, realiza-se em um tempo 
posterior ao da diegese. Desse modo, a narrativa apresenta a posição clássica da voz no passado, atendendo ao modelo de narração ulterior. Como todos os relatos, inseridos no discurso narrativo, referem-se a eventos já ocorridos, esse modelo de narração confere ao narrador o papel de organizador do universo diegético. Além disso, sua enunciação caracteriza-se pela presença de um "eu" que situa sua focalização no interior da história:

A mãe desse nosso hobbit - o que é um hobbit? Imagino que os hobbits requeiram alguma descrição hoje em dia. Uma vez que se tornaram raros e esquivos diante das Pessoas Grandes, como eles nos chamam. [...]. Agora vocês sabem o suficiente para continuarmos. Como eu estava dizendo, a mãe desse hobbit - isto é, de Bilbo Bolseiro - era a famosa beladona Tûk, [...]. (TOLKIEN, 1998, p.2).

Embora o narrador de Tolkien seja heterodiegético, ao posicionar sua voz dentro da história, define seu estatuto como de intradiegético de primeiro nível. Por sua vez, conforme Genette ([196-?], p.254), a orientação para o narratário demonstra preocupação em estabelecer ou manter com ele um contato, ou até um diálogo, correspondendo, ao mesmo tempo, às funções fática e conativa de Jakobson. Esse narrador, mais preocupado com seu público, ao se dirigir a ele, explicita o canal: o livro.

A opção do autor em eliminar a dicotomia entre "presença-oralidade" e "ausência-escrita" resgata, na narrativa, o papel do narrador oral "ao lado" do ouvinte. Ao simular essa proximidade, o autor explicita o pacto de leitura, por meio da cumplicidade, inserindo a ambiguidade e o jogo metaliterário. Assim, a voz que se apresenta nessa narrativa busca reproduzir por escrito os tons e as ênfases do relato oral, configurando o discurso como híbrido.

De acordo com Colomer (2003, p.109-10), o narrador, ao atrair a atenção do leitor para as convenções literárias ou em relação à materialidade do livro, força-o a não se envolver com o texto apenas do ponto de vista emocional, mas também a apreciá-lo em sua qualidade de construto. A metaficção nega que a linguagem seja invisível, e alerta contra a total identificação e absorção no livro, trata-se de um "[...] agente subversor da forma canônica da literatura infantil e juvenil e converte o leitor em colaborador autoconsciente, mais do que em um consumidor facilmente manipulável." (COLOMER, 2003, p.112). A obra ultrapassa, então, as fronteiras da teoria e da prática, envolvendo uma na outra e uma 
pela outra, sendo a história o cenário dessa problematização.

Pela leitura da obra, notam-se vazios intencionais que geram expectativa e tensão. O interesse do leitor é, justamente, capturado por esses vazios que solicitam posterior preenchimento. $\mathrm{O}$ anseio de estabelecer um diálogo com o leitor resulta da função comunicativa do texto. Graças a essa função, há pontos de indeterminação que, presentes no discurso do narrador e das personagens, conferem mistério à narrativa e solicitam do leitor implícito uma interação (ISER, 1999, p.107).

A conectabilidade do texto de Tolkien é rompida, ainda, pelas potências de negação. $O$ processo de comunicação é dirigido de maneiras diferentes pelos vazios e pelas potências de negação, embora ambos sejam instâncias controladoras desse processo. Os vazios ocultam as relações entre as perspectivas de apresentação do texto, assim incorporando o leitor ao texto para que ele mesmo coordene as perspectivas, sendo que sua atividade é, ao mesmo tempo, controlada pelo próprio texto. As potências de negação evocam dados familiares ou em si determinados, a fim de cancelá-los. Todavia, o leitor não perde de vista o que é cancelado e isso modifica sua posição em relação ao que é familiar ou determinado. Desse modo, os vazios e as negações do texto ajustam o processo interativo, fazendo com que o leitor situe a si mesmo em relação ao texto. Durante a leitura, ele precisa, o tempo todo, atualizar e modificar o objeto, alternando o ponto de vista de uma perspectiva de apresentação para outra e desenvolvendo novas expectativas.

Dessa forma, pode-se notar na afirmação: "Numa toca no chão vivia um hobbit. Não era uma toca desagradável, [...]: era a toca de um hobbit, e isso quer dizer conforto" (TOLKIEN, 1998, p.2), que há um vazio instaurado acerca do que é um hobbit e potências de negação nas características desse espaço. Ao negá-las, o narrador solicita um exercício de aproximação e afastamento, assim, ao instaurar uma nova definição, amplia o horizonte de expectativa do leitor, por meio de uma revisão de seus conceitos prévios.

A própria definição de um hobbit efetua-se por meio das potências de negação: "Eles são (ou eram) um povo pequeno, com cerca de metade da nossa altura, e menores que os anões barbados. Os hobbits não têm barba. [...] quase nenhum poder mágico, [...]. [...] não usam sapatos porque seus pés já têm uma sola natural semelhante a couro [...]." (TOLKIEN, 1999, p.2). O jogo semântico instaurado pelo discurso do narrador, feito por afirmações e negações, permite 
que o leitor projete de forma imaginária um hobbit, aproximando-o e afastando-o de si mesmo e dos anões.

O interesse do leitor é ampliado, ainda, pelo anúncio do futuro realizado por Gandalf que apresenta Bilbo como o "eleito" à aventura. Por meio dessa estratégia metaficcional, a narrativa volta-se sobre si mesma, antecipando que a história apresentada é a de um herói que alcançará o sucesso. $O$ viés metaficcional, aliás, aparece na própria efabulação que firma seus alicerces em um mundo construído por palavras, pois, graças a elas, Gandalf cativa um hobbit para a aventura e Bilbo resgata suas memórias, conservando-as em um livro.

O narrador, embora use tempos verbais pretéritos em seu discurso, porque o dado descrito é passado para ele, não sujeita as personagens a seu tempo. Antes, pelo emprego de advérbios temporais, como "agora", "de repente", procura narrar os fatos como se estes se realizassem ao mesmo tempo diante dos olhos das personagens e do leitor:

Agora estavam num belo apuro: todos arrumadinhos, amarrados em sacos, com três trolls furiosos (e dois com queimaduras e ferimentos memoráveis) sentados ao lado deles, discutindo se deviam assá-los devagar, fazer picadinho e cozinhálos, ou ainda sentar em cima deles, um por um, e esmagá-los e transformá-los em geléia; [...]. (TOLKIEN, 1998, p.38).

Como Bilbo é incapaz de definir a si mesmo e, sobretudo, seu lugar no universo, pois imperfeito e em busca de individuação, conquista o jovem leitor que se identifica com essa personagem e junto dela realiza um exercício de deduções, visando interpretar as reações que manifesta.

Tolkien utiliza-se, também, da estratégia do humor para definir suas personagens. Assim, Bilbo caracteriza-se como covarde e acomodado. Suas reações face à previsão de que pode correr perigo na jornada são hiperbólicas e cômicas: "[...] ajoelhado sobre o tapete da lareira, tremendo como gelatina derretendo. Então caiu duro no chão, e ficou gritando 'atingido por um raio, atingido por um raio!' [...]" (1998, p.16). O mago Gandalf, diante dessas reações afirma: "- Sujeitinho impressionável [...]. - Tem uns acessos estranhos, mas é um dos melhores, um dos melhores. Feroz como um dragão num aperto." (1998, p.17). Diante dessa afirmação de Gandalf, o narrador desautoriza seu discurso, dirigindo-se ao leitor em busca de sua adesão: "Se vocês alguma vez na vida viram um dragão 
num aperto, irão perceber que essa comparação só podia ser uma licença poética quando aplicada a qualquer hobbit [...]" (1998, p.17). As opiniões dos anões sobre Bilbo, - manifesta por Gloin: “- Para Gandalf está tudo bem [...], mas um acesso desses [...] seria o suficiente para acordar o dragão e todos os seus parentes, e matar a todos nós" (1998, p.17) -, coincidem com as do narrador e diferem das do mago. Assim, a narrativa aproxima-se do romance polifônico, pois cada personagem possui um ponto de vista, inclusive o narrador.

Esse narrador, por meio de seu discurso metaficcional, convoca o leitor a refletir sobre a própria narrativa e seu processo de construção. Contudo, no transcorrer das peripécias, Bilbo prova seu valor e o discurso de Gandalf mostra-se válido, revelando que ele sabe mais sobre o protagonista do que o narrador. Justifica-se, então, que Gandalf tenha instigado Bilbo a abandonar o sossego da vida familiar, convocando-o a partir para a inauguração de um mundo melhor e mais justo.

Essa detecção, pelo leitor, de discordância de opiniões entre as personagens, solicita-Ihe uma tomada de posição. Assim, ao desconfiar da capacidade do narrador, ele adere ao ponto de vista de Gandalf, confiando em sua sabedoria. Contudo, essa personagem também comete equívocos, além disso, ausenta-se em momentos cruciais da aventura, deixando Bilbo e os anões à própria sorte.

Cabe ao leitor da obra buscar entender o que Bilbo ignora, confiando somente em sua própria capacidade de percepção e desconfiando dos discursos apresentados na narrativa. Ao realizar a jornada com esse herói, o jovem leitor é convocado a sair da "toca", a rever seus conceitos prévios e, por isso, ampliar seu horizonte de expectativa em relação ao papel do narrador como controlador do universo diegético, detentor da verdade. Esse leitor, ao perceber que é capaz de tomar decisões e avaliar discursos, pode elevar sua autoestima e trazer seus conhecimentos para a realidade que o cerca. Trata-se, então, de um produto cultural útil sem ser utilitário, pois não institui verdades, trabalha criativamente com a linguagem, dialogando, com humor e ironia, com os contos de fadas tradicionais, as lendas e a mitologia, na apresentação de heróis que fracassam. Com essa estratégia, a obra possibilita ao leitor vários níveis de leitura.

O discurso do narrador não exagera a altura do nível culto, principalmente quanto ao vocabulário. Dessa forma, há equilíbrio entre o sumário narrativo e o diálogo das personagens que, adequados às suas características, são verossímeis. A ânsia de estabelecer dialogia com o leitor, por meio da linguagem in- 
formal, diminui o hiato entre a norma culta e a coloquial, e entre o discurso do adulto e o do jovem. Essa opção do autor conota sua intenção de clareza e entendimento o mais direto possível, em busca de conferir prazer à leitura.

O narrador apresenta a angústia de seus protagonistas em uma linguagem próxima à deles, utilizando-se do discurso indireto livre, a fim de cativar as emoções do leitor. Assim, transitam para o leitor o dilema dos heróis, sem explicá-los em suas causas e consequências, produzindo sua inclusão no drama da personagem: "O pobre Bilbo não podia suportar mais. Ao ouvir talvez nunca voltemos, começou a sentir um grito agudo vindo de seu interior, que logo irrompeu como o apito agudo vindo de uma locomotiva saindo de um túnel" (TOLKIEN, 1998, p.16).

O narrador tanto absorve o drama interior do herói, pois o expressa na sua sintaxe, quanto, como categoria textual, objetiva controlar a simpatia dos leitores em relação a determinadas personagens e em detrimento de outras. Para tanto, seleciona dados, organiza-os e prioriza certos eventos.

O desejo desse narrador em estabelecer uma comunicação com o leitor avulta em seu discurso sob a forma de um jogo criativo, permeado de referências. Já a cumplicidade com o leitor se efetiva pelo tom humorístico do discurso do narrador. Um exemplo desses referentes literários compartilhados aparece na cena em que Bilbo e os anões lutam contra os trolls. A performance do líder dos anões, Thorin, remete à ação heroica de Ulisses: "[...] apanhou um enorme gaIho com uma ponta toda em chamas; Bert [troll] levou aquela no olho antes que pudesse pular de lado" (Tolkien, 1998, p.35).

A narrativa apresenta-se, então, pela posse de uma tradição cultural conjunta, como um jogo comunicativo a ser compartilhado, reforçando essa cumplicidade pela distância reflexiva do humor. Para Aguiar e Silva, a metacomunicação literária "[...] exerce uma poderosa influência na conservação e na transformação da memória do sistema literário, condicionando a conformação do público leitor, à constituição de um determinado cânone de autores e de textos." (1993, p.331). Conforme o autor, por meio dessa comunicação, ocorre um processo de educação literária.

A obra de Tolkien pressupõe um leitor implícito inteligente, pois capaz de conferir significados simbólicos e de estabelecer relações intertextuais. Com essa pressuposição, a obra configura-se como um produto cultural menos protetor em relação a seus destinatários e mais inovador em suas características. 
Tolkien organiza o discurso de seu narrador e de seus personagens, fazendo uso de figuras de linguagem tanto no plano semântico e morfológico do texto, quanto no sonoro. $\mathrm{O}$ emprego desses recursos estilísticos possibilita ao leitor, pelo estranhamento e efeito de humor, o distanciamento e a reflexão sobre diferentes e novos significados que a criatividade pode conferir a um vocábulo, a fim de que este atenda à função poética e aos desejos do autor de criação de um código próprio.

O contato com a função poética da linguagem faculta ao leitor desautomatizar suas concepções acerca do uso da língua. Por sua vez, o emprego de neologismos convoca a sua participação enquanto coautor do texto, que precisa realizar operações cognitivas de ativação de seu conhecimento linguístico, a fim de decodificar o vocábulo criado. O leitor precisa reagir diante dele de forma ativa e inteligente para compensar o desvio:

- Caramba, Bert! Olha o que eu apanhei! - disse William.

- O que é? [...].

- Não sei, não! O que é você?

- Bilbo Bolseiro, um ladr... hobbit - disse o pobre Bilbo, todo tremendo [...].

- Um ladrhobbit? (TOLKIEN, 1999, p.35).

A intenção de Tolkien de capturar o interesse do leitor leva-o a situar as peripécias de seus heróis no interior de montanhas, tocas, florestas, em espaços desconhecidos, compostos por labirintos, que fazem parte da linha heroico-aventuresca. No universo paradoxal, construído pelos pares antitéticos vida/ morte, perigo/segurança, avultam todos os componentes que atraem o jovem, como o desconhecido, a liberdade de aventurar-se e o impulso em quebrar a rotina.

Pelo discurso indireto livre, o narrador funde seu relato ao do protagonista. Assim, a posição ideológica assumida por esse narrador não tem por objetivo apresentar a superioridade da enunciação do adulto sobre a do jovem. Esse narrador, embora dotado de focalização onisciente, evita penetrar no âmago das consciências, como em todos os meandros e segredos, relegando a avaliação moral, o comentário ideológico e o discurso didático a outras personagens. Desse modo, esse narrador de primeiro nível relativiza seu relato e permite à personagem narradora, de segundo nível, narrar seus conhecimentos, bem como suas 
apreciações dos fatos. Aliás, os comentários e julgamentos desta são tão válidos quanto os do narrador tradicional.

Pode-se observar, no transcorrer do relato, que o discurso do narrador de primeiro nível vai declinando, enquanto o da personagem-intradiegética, de segundo nível, ascende. Entretanto, o discurso desta também não se instaura soberano, porque sofre constantemente o assédio e o interrogatório de seus ouvintes. Como seus comentários e explicações decorrem das solicitações de outras personagens e não do desejo de lhes incutir valores, as personagens narradoras de segundo nível procuram se concentrar no cerne dos acontecimentos, valorizando a ação e evitando as digressões.

No discurso do narrador de primeiro nível, aparecem as mesmas qualidades que configuram os atributos de uma obra voltada para o público juvenil: a valorização da ação, o desprestígio das descrições e digressões, o emprego de uma linguagem coloquial destituída de intenções ideológicas ou ironias quando se refere às ações e aos anseios dos protagonistas. No texto, o narrador, sem avaliações implícitas, reproduz a consciência das personagens sobre o que pensam e sentem, levando o leitor a compartilhar a desorientação ou a inocência delas que devem evoluir e amadurecer ante seus olhos e em sua companhia.

Dessa forma, quando o narrador onisciente se sente impelido a avaliar moralmente os fatos, focaliza repentinamente o protagonista e funde sua voz com os pensamentos deste. Desse modo, uma espécie de voz conjunta é que emite juízos de valor sobre as condutas humanas descritas.

A relativização do papel do narrador não é simétrica à do recebedor. Se a duplicação do narrador o enfraquece, a multiplicação do recebedor fortalece a posição do leitor. Este encontra aliados, com os quais se identifica e nos quais se projeta. Por isso, o texto representa um reforço da posição do jovem, pois seu autor o reconhece como um leitor que impõe normas, na medida em que interfere, interrompe, interroga e julga as personagens, de acordo com suas necessidades e concepções.

Pode-se observar que, na obra, existem soluções comunicativas que se efetivam tanto no plano ideológico, quanto no linguístico. No plano retórico, prevalece: o cuidado em despir a língua de qualquer forma de rebuscamento, merecendo relevo a linguagem afetiva; o tom de coloquialidade, obtido pela aproximação da sintaxe das construções do discurso oral; e a espontaneidade, própria do discurso do jovem, no emprego de neologismos, onomatopeias e ex- 
pressões populares. No plano ideológico, por sua vez, o discurso liberal do narrador ativa o senso crítico do leitor acerca do que se propaga como "verdade" na sociedade, facultando-Ihe emancipação.

O discurso do narrador de Tolkien é atraente, pois descreve o mundo com certo grau de incerteza, não se posicionando como o adulto detentor da verdade e do conhecimento absoluto sobre a narrativa: "Receio que essa tenho sido a última vez que viram aqueles excelentes poneizinhos, [...]." (TOLKIEN, 1998, p.62).

Como se pode notar, a desmistificação da voz do adulto, a cumplicidade com o narrador, a distância em relação à obra, bem como a ambiguidade de significados, configuram uma literatura que intensificou o propósito de oferecer um produto que confere prazer aos seus leitores e uma nova forma de exploração da realidade.

\section{Considerações finais}

Pelo exposto, pode-se deduzir que $O$ hobbit favorece a ampliação do imaginário, por meio da fusão de elementos originários da Antiguidade, da história mundial, da mitologia grega e dos grandes mitos e lendas. A manutenção do fantástico na narrativa se efetiva, por meio da linguagem que cria uma atmosfera onírica. Por apresentar um protagonista que precisa superar obstáculos, descobrir seus potenciais, suas origens e, principalmente, cumprir uma missão em prol do bem comum, aproxima-se das histórias de encantamento primitivas que são concebidas pela psicologia e pela psicanálise como uma representação do trajeto humano pela vida, ou seja, como ritos de passagem, por isso, propicia uma identificação com o jovem leitor em fase de transição.

A opção do autor por um narrador liberal e, por consequência, pela manutenção de uma estrutura comunicativa, confere ao seu texto caráter emancipatório. Desse modo, sua obra incentiva a criatividade e o posicionamento crítico, convocando o leitor a uma tomada de posição face ao que lhe é apresentado. 0 valor emancipatório desse texto também advém do fato de apresentar de forma simbólica e essencial os principais desejos e tensões dos jovens em estágio de desenvolvimento.

A presença de intertextualidade, vazios e potências de negação, por sua vez, conota um receptor perspicaz, capaz de usar sua memória para o resgate das 
referências e seu poder de síntese, inferência e dedução para a resolução dos mistérios que exigem o preenchimento de lacunas, bem como constantes reformulações de hipóteses. O prazer da leitura advém dessa comunicabilidade, desse jogo ficcional na remissão a outras narrativas e, também, da presença de um narratário que configura o papel do narrador como um contador de história ao lado do leitor.

A obra, pela sua complexidade narrativa que se manifesta, pela focalização direcionada para um protagonista ainda em fase de definição de sua individualidade; pelas vozes simultâneas e intradiegéticas tanto de primeiro, quanto de segundo nível; e pelo anacronismo na ordem do discurso, não tem complacência com o leitor.

A enunciação de seu narrador favorece a revisão de conceitos prévios e amplia o horizonte de expectativa em relação ao papel dessa personagem que difere do controlador do universo diegético, detentor da verdade. Aliás, nesse texto, a verdade jamais é absoluta, nem definitiva, por isso o mundo é descrito com certo grau de incerteza. Assim, como não existem verdades, os acertos não são absolutos, pois os erros podem levar à aprendizagem, bem como o quebrar de regras e normas. Prevalece, portanto, na obra, uma crítica a um modelo moral único.

Sua superposição de temas e de modelos literários, na narrativa, revela a tentativa de inserção cultural, por meio da transmissão de um legado cultural. Como produção juvenil, a obra se propõe a cumprir uma formação cultural do jovem, favorecendo à sua educação social, por meio de uma narração ordenada da interpretação do mundo.

A exploração de temas como: medo diante do desconhecido; restrição de convívio social; angústia diante de desafios e em relação a acontecimentos futuros, sobre os quais não se tem controle; receio de não atender às expectativas; insegurança; não aceitação no grupo a que se pertence, entre outros, revelam a contemporaneidade dessa produção cultural e sua sintonia com seu leitor.

A obra agrada ao jovem leitor porque é marcada pelo humor, pela ambiguidade e pela fantasia. $\mathrm{O}$ gosto pela narrativa fantástica, por certos medos "deliciosos", bem como, por algumas formas de cômico, dissipa os medos do jovem leitor diante da autoridade, assim também, por semelhante método catártico, cura-o de angústias mais complexas e mais difíceis de serem definidas (HELD, 1980, p.98). 
Detectar a existência de elementos atraentes na obra de Tolkien é relevante, pois permite reconhecer sua potencialidade para a oferta de prazer na leitura. Para o jovem, esse prazer é muito importante, pois profundamente ligado a uma atitude afetiva. Graças a esse processo, o livro pode lhe deixar marcas, traços e impressões que servirão de ponto de partida para novas leituras. Pode-se deduzir, então, pelo exposto, que $O$ hobbit pode exercer esse papel de estímulo incessante.

\section{Referências Bibliográficas}

AGUIAR, Vera Teixeira de. O bruxo e os leitores. In: RETENMAIER, Miguel; JACOBY, Sissa (orgs.). Além da plataforma nove e meia: pensando o fenômeno Harry Potter. Passo Fundo: UPF, 2005, p.11-22.

AGUIAR E SILVA, Vitor Manuel de. Teoria da literatura. 8. ed. Coimbra: Almedina, 1993. COLOMER, Teresa. A formação do leitor literário: narrativa infantil e juvenil atual. Trad. Laura Sandroni. São Paulo: Global, 2003.

FERREIRA, Eliane Ap. Galvão Ribeiro. Construindo histórias de leitura: a leitura dialógica enquanto elemento de articulação no interior de uma biblioteca vivida. Assis, 2009. 456p. Tese (Doutorado em Letras) - Faculdade de Ciências e Letras, Campus de Assis, Universidade Estadual Paulista "Júlio de Mesquita Filho".

GENETTE, Gérard. Discurso da narrativa. Trad. Fernando Cabral Martins. Lisboa: Vega, [196-?].

HELD, Jacqueline. O imaginário no poder: as crianças e a literatura fantástica. Trad. Carlos Rizzi, São Paulo: Summus, 1980.

ISER, Wolfgang. $O$ ato da leitura: uma teoria do efeito estético. Trad. Johannes Kretschmer. São Paulo: Ed. 34, 1999, vol. 2.

SITE OFICIAL DA WARNER. Disponível em: <http://wwws.br.warnerbros.com/thehobbitpart1/dvd/\#content=home>. Acesso em: 3 jun. 2014.

SMADJA, Isabelle. Harry Potter: as razões do sucesso. Trad. Ângela Ramalho Viana e Antônio Monteiro Guimarães. Rio de Janeiro: Contraponto, 2004.

TODOROV, Tzvetan. As estruturas narrativas. Trad. Moysés Baumstein. 2. ed. São Paulo: Perspectivas, 1970.

TOLKIEN BRASIL. Disponível em: <http://tolkienbrasil.com/noticias/sobre-livros/senhor-aneis-livro-vendido-mundo-ate-momento/>. Acesso em: 6 jun. 2014.

TOLKIEN, John R. R. O hobbit. Trad. Lenita Maria R. Esteves. 2.ed. São Paulo: Martins Fontes, 1998. 
WHITE, Michael. Tolkien: uma biografia. Trad. Alda Porto. Rio de Janeiro: Imago, 2002. ZILBERMAN, Regina. A literatura infantil e o leitor. In: ; MAGALHÃES, L. Cadermatori. Literatura infantil: autoritarismo e emancipação. 2.ed. São Paulo: Ática, 1984, p.61-134. 